\section{Organização e Métodos}

Por Geraldo Inácio Mac-Dowell dos Passos Miranda. São Paulo, Atlas, 1973. 325 p. Bibliografia extensa, atualizada.

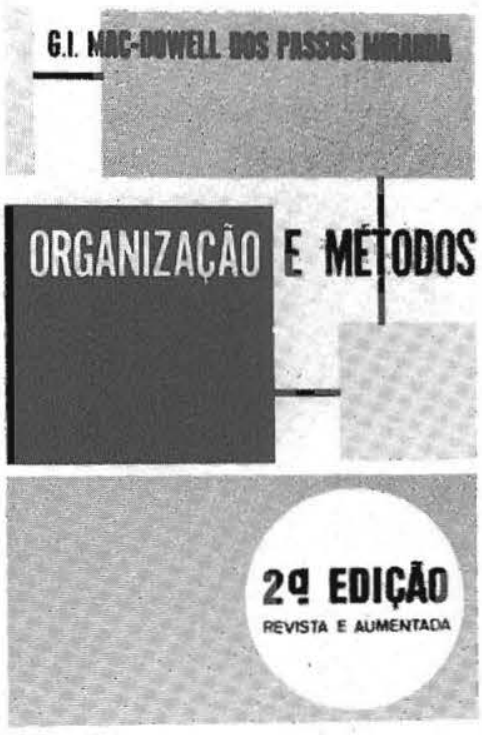

EDITORA ATLAS S.A.

Deve a área de organização e métodos ser tratada pelo departamento de administração da produção de uma faculdade de administração de empresas e administração pública, ou deve ela ser atribuída ao departamento de administração geral? Essa pergunta ocorre-me ao escrever esta resenha. 0 livro é dividido em 21 capítulos, e será possivel ao menos dar em termos percentuais aqueles que são "produção" e aqueles que são "administração". Na Fundação Getulio Vargas de São Paulo a solução foi bastante salomônica, pois professores-engenheiros militam no departamento de administração geral.

Mas, eis os capítulos:

\section{Introdução}

2. Os tradicionalistas - seus conceitos e princípios

3. ${ }^{\circ}$ Os pioneiros da organização 4. ${ }^{\circ}$ Síntese de algumas teorias modernas de organização

5. Tipos clássicos de estrutura - modernas concepções sobre estruturas
R. Adm. Emp.,
Rio de Janeiro,

6. Assessoramento, centralização; descentralização e concentração e desconcentração - sistemas

7.0 Fases do processo de organização ou reorganização

8. Levantamento e análise

9. Planejamento

10. Implantação e controle dos resultados

11. ${ }^{\circ}$ Problemas de constituição de um empreendimento

12. Elaboração de projetos para pequenas e médias empresas

13..$^{\circ}$ Simplificação do trabalho

14. Representação gráfica

15. Modelos-formulários e fichas

16. Administração de material

$17 .^{\circ}$ Arquivamento

$18 .^{\circ}$ Relatórios e manuais de serviço

19. Documentação

20. Custos

21. Noções básicas sobre administração de pessoal

Apêndice: Normas da ABNT Bibliografia

Como se nota, falta índice remissivo, grave falta num livro que se destina a administradores, que terão eventualmente a necessidade de rapidamente procurar resposta a uma pergunta que possa aparecer repentinamente.

Antes de criticar a obra é necessário fixar os limites impostos pelas 325 páginas e determinar bem o universo de eventuais leitores aos quais se destina. Pelo prefácio o livro tem por objetivo servir de texto nas faculdades de administração de empresas e escolas de serviço público. O livro tem, na opinião do autor (e na do resenhista também), cunho didático e deve responder às indagações dos alunos. 0 autor conseguiu tal intento, indubitavelmente. A compressão, porém, de muita matéria num espaço escasso deixou de lado alguns assuntos, incompletos outros, mas surpreendentemente conseguiu a síntese - é inacreditável a riqueza de conteúdo. Se portanto a resenha faz crítica, é porque o próprio autor pede isso no prefácio da sua obra, com o intuito de colaborar para a maior eficiência do ensino e da distribuição da cultura administrativa no Brasil.

Para responder à primeira dúvida - se produção ou administração - observe-se que metade do $110^{\circ}$ capítulo (p. 138) tem conteúdo em administração geral. De lá até a p. 200, fim do capítulo 14, é produção, que continua do capítulo 16 (p. 220 a 238). Os capítulos 17 (arquivamento), 18 (relatórios) e 19 (documentação) somam 47 páginas de administração geral, seguidas de 30 páginas sobre custos e administração de pessoal. No total, terça parte da obra é dedicada à produção e $2 / 3$ à administração. Portanto, o estudo é da área de administração.

Para os leitores interessados em conhecer o estudo do mesmo assunto do ponto de vista do engenheiro recomenda-se principalmente o primeiro volume de Edward V. Krick, Métodos e sistemas, livros técnicos e científicos, da Editora Rio, edição de 1971, tradução do original americano de 1962. Mas, como se nota pelo próprio título, o autor deixou fora a parte de "organização".

Quanto à divisão da matéria, acredita-se que a inclusão de 63 páginas de resumo das teorias de organização justifica-se no caso de um aluno ou leitor autodidata não poder recorrer a uma obra mais extensa sobre o assunto ou ir às fontes diretamente. 0 Prof. João Bosco Lodi tem um livro, História da Administração (São Paulo Pioneira, 1972), com um resumo melhor, que apresenta de maneira mais extensa as escolas e suas filosofias; a leitura correlata desse livro se recomenda.

Nessa parte, uma pequena ressalva: tem-se a impressão de que o "mito de Henry Ford", cuidadosamente estabelecido por um sistema de relações públicas, penetrou no livro; recomenda-se muito a leitura de Keith Sward, The legend of Henry Ford (Atheneum 1968, escrito em 1948). Assim, na página 55 desse livro, está eșcri-

$$
13(3): 152-162 \text {, }
$$


to: "These critics were about to witness a brilliant demonstration of the economy of high wages... What escaped most of these bewitched observers was that Ford and Couzens were practical businessmen first and men of good will second... Ford's men were producing more efficiently and for less money per unit of work performed... the company had taken its pick of labor." Ou nas proprias palavras da autobiografia de Henry Ford: "O pagamento de 5 dólares por um dia de trabalho de 8 horas foi um dos melhores métodos de diminuição de custos jamais feito por nós" (p. 147, da autobiografia). Assim, faço exceção ao louvor a Henry Ford na parte de tarefa social do empregador, prestação de serviço a coletividade e, em parte, aos salários elevados que correspondem ao speed-up produtivo.

Antes de parecer enfadonho deve ser mencionado 0 fato de que a Ford Motor Company se recusou, de 1933 a 1935, a colaborar com o governo dos Estados Unidos no National Industrial Recovery Act, e tomou em seus serviços para quebrar (literalmente) os sindicatos - prisioneiros perdoados so para isso das prisōes do Estado de Michigan - criando uma eficiente policia de fábrica."

O $5 .^{\circ}$ capltulo sobre tipos clássicos de estrutura é excelente; 0 6. 0 pode dar origem a algumas observaçōes: o resumo de três páginas sobre "sistemas". A definiçăo é válida (p. 94), sendo uma das inúmeras apresentadas. Mas como na época de computador, onde até o ensino se tornou "sistema", 0 estudo do assunto deve alcançar profundidade; mesmo no campo restrito de um curso introdutório, há urgente necessidade de ampliaçăo, com exemplos. Como ficaria interessante neste ponto o sistema "compras" do governo, com as atividades e informaçóes de "orçamento", "consumo", "apuraçăo da necessidade", "decisão entre concorrência ou tomada de preços", "tribunal de contas", "entrega e controle de quantidade e quali- dade", etc... Da maneira como está, a referência só satisfaz a quem quer responder num teste de serviço público a uma pergunta de múltipla escolha. As figuras 8 e 9 do mesmo capítulo säo de dificil leitura, pela evidente limitação do espaço, recomendandose em futuras ediçōes o caro (mais caro) sistema de encarte de uma folha dobrada para fora.

- capitulo 7 e uma introduçăo em três páginas aos quatro capltulos subseqüentes e poderia ter sido melhor realizado como a introdução de uma "seçăo" do livro constituldo dos quatro capitulos. Isso, entretanto, seria discutir a forma. Os capitulos de Levantamento e análise (8) e Plam nejamento (9) săo excelentes. Sucintos e claros, dão a idéla perfeita de como se deve proceder. Mostram antes de tudo também a cultura do autor, que torna a leitura mais amena. São perdoáveis pequenos senöes, como por exemplo, em se tratando de imóveis, falta considerar "alugar ou imobilizar capital", um problema importante para a industria e mesmo para o Estado; ou de pessoal, onde o funcionário é chamado de "servidor" como mandava 0 antigo DASP. 0 servidor aparece até na linguagem administrativa da Fundação Getulio Vargas e tem a conotação da espinha dobrada para o "superior", como diz Pierre Weil e Tompakow, em 0 corpo fala, da Editora Vozes. Ou como afirma o Pequeno dicionário da língus portuguesa, servidor, s.m. é aquele que serve; criado; doméstico; obsequiador; funcionário-público (jur.). Q.E.D.

O capitulo sobre planejamento deixa fora alguns assuntos primordiais como cronogramas, CPM ou PERT, e coloca "condições de instalação", citando o Lighting hand book da Westinghouse. Incluindo tal assunto, devem ser mencionados os livros da Philips, que no Brasil possui traduçöes para o espanhol da sua rica biblioteca de iluminação e presta excelente serviços (grátis) de consultoria. Seria eventualmente mais adequado incluir nos próximos números alguns estudos fisiológicos da ergonomia, sobre trabalho, calor e luz, em lugar desse resumo.

O capltulo 10, escrito em colaboraçăo com o Com. Alvarez, deve ser aumentado, incluindo auditoria pelos tribunais de contas e nas empresas de serviço pubblico ou em empresas com açōes no mercado, como no caso da CSN, Petrobrás, etc. por auditores particulares. A parte psicológica da resistência à mudança pode, eventualmente, ser transferida para uma leitura colateral.

O comentário feito a respeito do capitulo 7 também serve para - 11. . E uma introdução a uma seçäo do livro. Em seguida, no projeto para a pequena e média empresa aparece o PERT, que é transferido para a apresentação gráfica, acreditando o autor destas linhas, que o melhor seria tratar mais de cronograma de barras (Gantt). A localização nāo leva em conta incentivos tipo Sudene e Sudam, pois trata-se de livro dedicado à administração públi$\mathrm{ca}$, em sua ênfase. otimo o capítulo da simplificação do trabatho, resumido e claro. Parabéns pelo capitulo de apresentaçäo gráfica. Excelente e preenche a lacuna proverbial. 0 mesmo pode ser dito do capitulo de modelos, formulários e fichas; claro, sucinto e necessário.

- capitulo 16, Administraçāo de material, precisa ser reformulado a luz do regulamento atual, mostrando claramente como proceder quando a compra está abaixo de cinco salários mlm nimos, de 5 a 50 (tomada de preços) e acima de 50 (concorrência). Sobre a ênfase dada nesse capitulo à guarda, armazenagem e controle pode-se discutir, com proveito, principalmente, os inúmeros problemas de "contratos" e de "compra por concorrência que nāo apresente vencedor de preço menor". Os capitulos $17 \mathrm{e}$ 19 são dirigidos ao serviço público, que exige sua "documen- 
tação"; o sistema Dewey para bibliotecas é muito bem apresentado.

o capítulo 20 , que aborda os custos, é bom e suficiente, e o 21 , sobre o pessoal, sofre de falta de espaço para tratar meIhor a avaliação de cargos, mas, dedica outra vez espaço à iluminação, com apresentação da tabela da General Electric.

0 autor esmerou-se em resumir objetivamente o livro e isto, sem dúvida, ele conseguiu. Contudo, há necessidade de leituras colaterais e suplementares. Mas - livro preenche as suas necessidades e pode ser recomendado para cursos de nivel universitário. A apresentação gráfica satisfaz, exceto pela redução das figuras já mencionadas. Por outro lado, onde está a uniformidade de uso de maiúsculas e minúsculas no meio de frases e títulos? Este problema é de revisão. Por exemplo, na página 107 e seguinte, Diretoria é escrita assim com D maiúsculo; "órgão superior", no entanto, está em minúsculo. Deve ser a sombra do "servidor" mencionado anteriormente, doutorando os maiúsculos de cima. $\mathrm{Na}$ página 85 os "órgãos normativos" variam, são maiúsculos entre aspas e minúsculos quando sem elas. A palavra staff passou a "estafe", satisfazendo assim a turma que prefere adotar leiaute, uisque, etc. Melhor seria eliminar staff e dizer assessoramento ou assessoria, de vez.

Em resumo, um livro pequeno, útil, prático que tem algumas limitações, que é, no entanto, ex-

154 celente para a introdução ao complicado campo de "Organização e Métodos" (maiúsculo) ensinando em escolas de administração pública (para empresas a ênfase deve ser diferente). Parabéns ao autor pela leitura de muitos livros e a introdução de vasta soma de conhecimentos em poucas páginas.

Kurt Ernst Weil

\footnotetext{
- Baughman, James P. The history of American management. cap. de Sidney Fine.
}

\section{Management Enzyklopaedie}

Pela Editora Verlag Moderne Industrie, Wolfgang Dummer, Munique 8, Alemanha, 1972. Enciclopédia em seis volumes sobre o conhecimento de management de nossos tempos. Diversos autores. Total de 7635 páginas com duas colunas contendo 589 verbetes desenvolvidos alfabeticamente. Indices no $6 .^{\circ}$ volume contendo, em ordem alfabética: nome dos autores; todas as contribuições (verbetes); reunião dos verbetes em áreas ou disciplinas; indice por palavras-chaves $e$ áreas; "o mais completo" indice de literatura de administração em língua alemã (segundo a opiniäo da editora). Preço: DM 165 por volume.

Os volumes são completamente alfabetados e possivelmente uma reprodução dos títulos dos verbetes por volume traduzido para o português mostrará o teor do livro:

Volume 1: Planejamento de vendas - Banco Central

Volume 2: Cash-flow - Futurologia

Volume 3: Serviço a hóspedes - Cibernética

Volume 4: Manutenção de estoques - Publicidade

Volume 5: Qualidade - Controle de, - Vendas - procedimentos de,

Volume 6: Vendas - relatórios de, - Indústrias fornecedoras. Indices.

E extremamente difícil escrever sobre uma obra de seis volumes, da qual só se tem em mãos o último e quando essa obra é uma enciclopédia que trata de assuntos tão diversos como "Depreciação", "Tratamento de esgotos industriais", "Estudos de tempos", "Energia atômi- ca", "Especulação de bolsa", "Psicologia das cores", "Grafologia", "Purificação do ar", "Microfilmagem", etc.

A crítica de cada artigo, que foi escrito por um especialista, deveria ser dada para um especialista. No entanto, pelo estudo de um volume, algumas vantagens da obra aparecem imediatamente: tratamento claro, matemático (onde tal é necessário), redação que evita duplicação de conceitos, e tendência a ser prática e eficiente. $O$ especialista em determinada área irá, sem dúvida, encontrar falhas no tratamento do "seu assunto", mas tais faIhas são realmente poucas.

0 estudo minucioso de alguns verbetes permite-nos chegar à conclusão de que temos uma obra de grande utilidade para tomar conhecimento básico do assunto. Além disso, a extensa bibliografia leva o leitor à especialização. Como exemplo, podemos citar alguns verbetes:

"Planejamento de crescimento (Expansão) (Desenvolvimento)" - inicialmente, a definição como "passagem de objetivos para algo maior ou mais ambicioso" está muito interessante e certa; em seguida, há fluxogramas de "Sistemas" de crescimento para uso até em computador; e mais adiante, um capítulo sobre filosofia da empresa em relação à inovação. $O$ verbete estuda, em seguida, a estratégia do crescimento como uma matriz de decisão de planejamento, com conseqüências quantificadas tanto quanto possivel, matriz produtomercado. A estratégia financeira é analisada a partir de um gráfico de ponto de paridade, seguida de um estudo do efeito sinergético do crescimento.

O verbete "Marcas e símbolos" trata da legislação alemã sobre - assunto e deve ser lido em conjunto com o verbete "Embalagem", no qual logotipos são extensivamente demonstrados, sofrendo inclusive uma análise de pesquisa motivacional de tipo 